\section{Repulsion between calcite crystals and grain detachment during water-rock interaction}

\section{Y. Levenson ${ }^{1}$, S. Emmanuel ${ }^{1 \star}$}

OPEN 2 AcCESS

\section{Abstract}

doi: 10.7185/geochemlet.1714

Weathering in carbonate rocks is often thought to be governed by chemical dissolution. However, recent studies have shown that mechanical detachment of tiny grains contributes significantly to the overall surface retreat. Whether this detachment is caused by shear forces acting at the surface, or repulsive forces acting between grains, was not known. In this study, we used atomic force microscopy to examine the mechanism of grain detachment and we demonstrate that it occurs even in the absence of shearing fluid flow. This suggests that the removal of grains from rock surfaces can be caused by repulsive forces between calcite grains. Although these repulsive forces are expected to be sensitive to the ionic strength of the solution, we did not find enough evidence to demonstrate a correlation between slinty and the frequency of gin detach ent. Importantly, our findings suggest bet that grain detach a nt occurs during water-rock interaction under low flow conditions over a oil recovery in carbonate formations.

Received 27 September 2016 | Accepted 9 January 2017 | Published 31 January 2017

\section{Introduction}

The geochemical interaction between carbonate rocks and reactive fluids strongly influences the way many rock formations weather. Although chemical dissolution of carbonate minerals plays a key role in weathering (Morse and Arvidson, 2002; Ford and Williams, 2007; Morse et al., 2007), some studies have suggested that micrometre- and even nanometre-scale mechanical processes can be equally important (Cooper et al., 1992; Vleugels and Van Grieken, 1995; Luquot et al. 2014. Emmanuel et al. 2015). For example, Levenson and Emmanuel (2016) recently showed that $\sim 40 \%$ of the mass removed during weathering experiments on fine-grained limestone is attributable to the detachment of grains

1. Institute of Earth Sciences, The Hebrew University of Jerusalem, Edmond J. Safra Campus, Givat Ram Jerusalem 91904, Israel

Corresponding author (email: simonem@cc.huji.ac.il) from the rock surface, a process which is preceded by chemical dissolution along grain boundaries. While those experiments were able to quantify this chemomechanical process, the actual mechanism that causes tiny grains to detach from the surface was unclear. Because all the experiments in which grain detachment was observed were carried out in a flowing fluid, shear forces at the solid-water interface were suggested as a possible factor (Levenson and Emmanuel, 2016). However, the frequency of grain detachment events did not increase with flow rate, hinting that shearing might not be the only mechanism influencing grain detachment.

Recently, Røyne et al. (2015) showed that in the presence of water, calcite grains repel each other. This process could weaken carbonate rocks. These repulsive forces are likely to be related to water adsorption on the crystal surfaces or to the electric double layer (Nara et al., 2014; Røyne et al., 2015) but in both cases, decreasing the concentration of dissolved ions is expected to increase the degree of repulsion. Such intergranular repulsion could be an important factor in calcite grain detachment from the surface of rocks during weathering, but whether or not repulsive forces do in fact shape reacting rock surfaces has yet to be determined.

The aim of this study was to isolate the effect of repulsive forces on grain detachment. We present the results from experiments carried out under zero flow conditions, to exclude the influence of shear forces. We also considered the impact of ionic strength and the implications of our results for rock weathering and geological carbon capture.

\section{Methods}

We used atomic force microscopy (AFM), which provides nanometre-scale resolution and in situ imaging in fluid environments. This technique has already been used to examine grain detachment in carbonate rocks (Emmanuel and Levenson, 2014; Levenson and Emmanuel, 2016), although in those previous studies, all experiments were carried out under constant fluid flow. Each sample was prepared from a $5.5 \mathrm{~mm}$ diameter core of Solnhofen micritic limestone that was embedded in a Plexiglas disk and polished with an ATM Saphir 520 single wheel grinder with a fluid polishing compound containing one-micrometre diamond particles. After polishing, the sample was rinsed with deionised water and wiped with ethanol. To create an inert datum, the samples were partially covered with a $150 \mathrm{~nm}$ layer of gold.

Once prepared, the sample was sealed in a fluid imaging cell on the AFM scanner (Veeco Multimode 8 AFM with a NanoScope V controller and NanoScope 8.15 software). Solutions were injected periodically into the system using a syringe pump. An initial $30 \mathrm{~min}$ pulse at $2 \mathrm{ml} \mathrm{hr}^{-1}$ was followed by alternating periods of no flow, i.e. $0 \mathrm{ml} \mathrm{hr}^{-1}$ (60 min), and flow at $2 \mathrm{ml} \mathrm{hr}^{-1}(15 \mathrm{~min})$. 
To keep the solutions undersaturated with respect to calcite during the intervals of zero flow, we used the chelating agent ethylenediaminetetraacetic acid (EDTA disodium salt dihydrate, crystal, BAKER ANALYZED® ACS Reagent) at a concentration of $2 \mathrm{mM}$ in all experiments. The addition of EDTA accelerates dissolution, although it does not affect the overall dissolution mechanism (Fredd and Fogler, 1998; Oelkers et al., 2011). To change the ionic strength of the solutions, we used $\mathrm{NaCl}$ (BAKER ANALYZED® ACS Reagent) at concentrations in the range $0-500 \mathrm{mM}$ (Table S-1). The $\mathrm{pH}$ of the solutions was 4.7-5.1. A total of 12 experiments was carried out.

To track the evolution of the limestone surface, the sample was imaged continuously during the experiments with silicon nitride probes (Bruker ScanAsyst Fluid+). Scans of $20 \mu \mathrm{m} \times 20 \mu \mathrm{m}$ regions were performed at a line rate of $1 \mathrm{~Hz}$ with a resolution of $256 \times 256$ pixels using the Peakforce ScanAsyst non-contact imaging method. Two imaging modes were recorded: Peakforce Error mode, which produces a pseudo-3D image emphasising topography, and topographical mapping mode, which provides the precise height of the surface. In the data shown here, the gold surface was used as a reference to register the data in the $x, y, z$ planes. In some cases, the surfaces of the samples were imaged at the end of the experiments using environmental scanning electron microscopy (ESEM FEI Quanta 200)

Data analysis was carried out using ESRI ArcGIS software implementing similar methods to those described by Levenson and Emmanuel (2016). Large topographic changes between sequential scans allowed us to count grain detachment events, which were defined as regions with lateral spatial dimension $>300 \mathrm{~nm}$, that had undergone vertical change in topography between scans of at least $100 \mathrm{~nm}$. The events were detected by subtracting the topography of the second image in the sequence from the first. The events were counted manually. While even smaller grains could detach from the surface, this threshold provided a minimum estimate for the number of events.

\section{Results and Discussion}

In each experiment, we observed a significant number of grain detachmen events, both during fluid flow and during stagnant periods (Fig. 1). Grain detachment during periods of no flow indicates that fluid shear forces are not the only mechanism for removing grains from the rock surface. Because the frequency of detachment events did not increase during flow (Fig. 2), shearing could even play a minor role in grain detachment. Rather than directly dislodging grains from the surface in our experiments, flow probably replenishes the undersaturated solution in contact with the rock, thereby facilitating dissolution along grain boundaries.
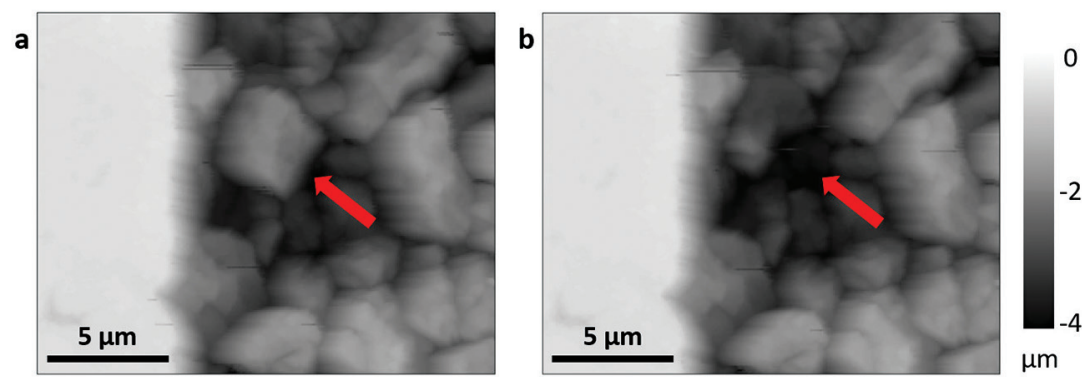

Figure 1 Topographic maps obtained using AFM (a) before and (b) after a grain detachment event (indicated by the red arrow) during zero flow. In both images, the smooth region to the left of the field was masked by gold. The experiment was carried out in a solution of $500 \mathrm{mM} \mathrm{NaCl}$.
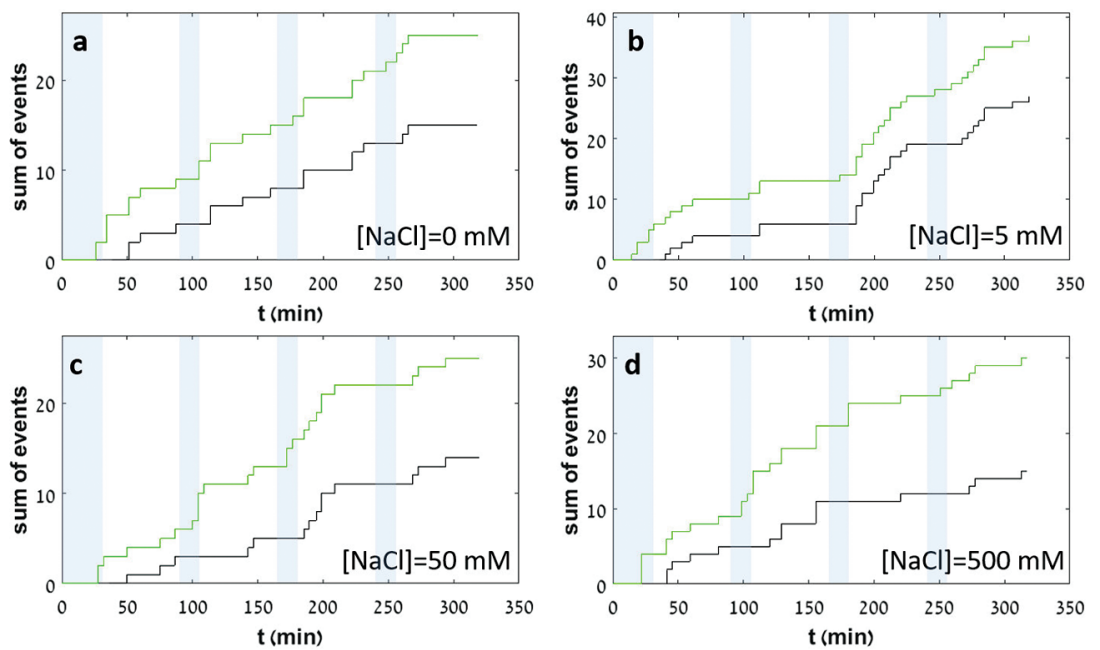

\section{- all detachment events
- detachment events during no flow}

Figure 2 Cumulative grain detachment events versus time in four representative experiments carried out at different salinities. Light blue bars indicate periods of flow, while white regions indicate periods of no flow. Numerous events are observed in all the experiments during zero flow conditions.

While grain detachment was clearly seen in the experiments during periods of zero flow, it is possible that grains could be plucked from the surface as a result of attractive van der Waals forces acting between the AFM tip and 
the calcite grains. Although not measured directly in this study, such forces are estimated to be on the order of $2 \mathrm{nN}$ in water (Lomboy et al., 2011). DVLO theory predicts that the maximum pressure resulting from double layer repulsive forces acting between surfaces in a calcite saturated fluid is $2.8 \mathrm{kPa}$ (Røyne et al., 2015). Thus, a calcite grain that is $1 \mu \mathrm{m}$ in diameter, with a grain-grain contact area of $5 \mu \mathrm{m}^{2}$, is expected to experience a repulsive force of $\sim 14 \mathrm{nN}$ caused by double layer repulsion. Røyne et al. (2015) reported repulsive pressures as high as $23 \mathrm{kPa}$, suggesting that the repulsive force for a 1- $\mu \mathrm{m}$ grain could be greater than $100 \mathrm{nN}$. Because the tip-grain force is smaller than the forces expected for grain-grain interaction, intergranular repulsive forces are likely to dominate the behaviour of micrometre-sized calcite grains. However, this comparison does not rule out the possibility that the tip affects our measurements, especially for smaller calcite particles.

To shed more light on this issue, after the experiments were terminated, we compared areas that had been scanned continuously during the experiments with areas that had not been scanned. If the AFM tip were responsible for removing grains from the surface, we would expect areas that had been scanned continuously to be rougher than regions that had not been imaged. However, we found no significant difference in the roughness (Fig. S-1), suggesting that AFM scanning does not have a major impact on the evolution of surface topography.

In addition to the roughness measurements, we also carried out five additional experiments in which regions of the limestone surface were imaged once with the AFM at the beginning of a period of zero flow. In each experiment, between 1 and 3 different regions were imaged. After an hour of no flow, the experiment was terminated and imaged with ESEM, and then scanned again with AFM under dry conditions. In 9 of the 13 scanned regions, we found examples where grains present at the beginning of the period of zero flow were absent from both the ESEM and AFM images, indicating that the grains were not removed by interaction with the AFM tip (Fig. S-2).

Repulsive forces between calcite crystals, caused by water adsorption or the electric double layer (Nara et al., 2014; Røyne et al., 2015), should be sensitive to the ionic strength of the solution. Specifically, increasing ionic strength is expected to decrease the repulsion between the grains and this is expected to result in a lower frequency of grain detachment events. However, in the range that we tested, there was no significant correlation between ionic strength and the frequency of grain detachment during periods of zero flow $\left(R^{2}=0.006\right.$; Fig. 3$)$. Because the AFM experiments provide a limited field of view, which results in a statistically small number of detachment events, minor effects resulting from changes in ionic strength could be masked by the relatively large variability we observe in our experiments.

Another reason for the lack of correlation between the frequency of grain detachment events and ionic strength could be related to the rate of chemical dissolution. Because grain detachment is a chemo-mechanical process, changes in the rate of dissolution at crystal surfaces and along grain boundaries would impact the frequency of events. If increasing ionic strength were to cause the dissolution rate to increase and the repulsive forces to decrease, there might be no net change in the observed rate of grain detachment. Some studies have indicated that ionic strength influences calcite dissolution rates (Buhmann and Dreybrodt, 1987; Gledhill and Morse, 2006; Ruiz-Agudo et al., 2010). However, in the salinity range that we tested, we found no significant effect $\left(R^{2}=0.16\right.$; Fig. 4$)$ but this could be a result of the far from equilibrium conditions in our experiments.

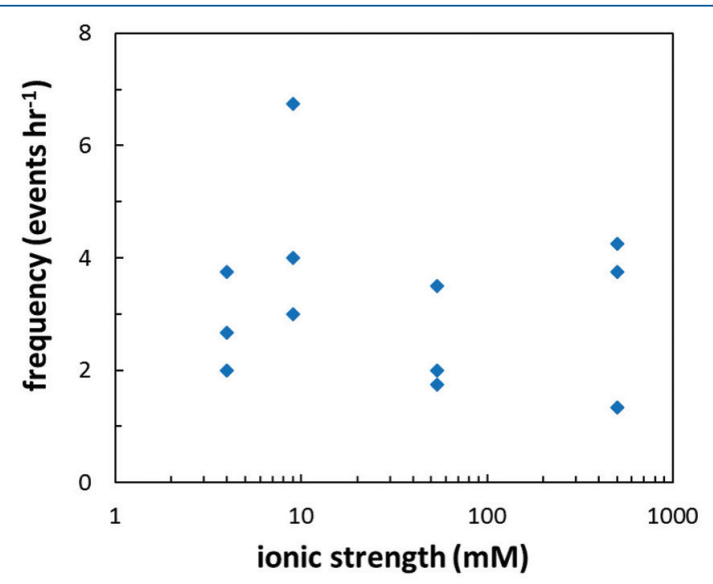

Figure 3 Frequency of grain detachment events during zero flow versus the ionic strength of the solution. There is no significant correlation between the two parameters.

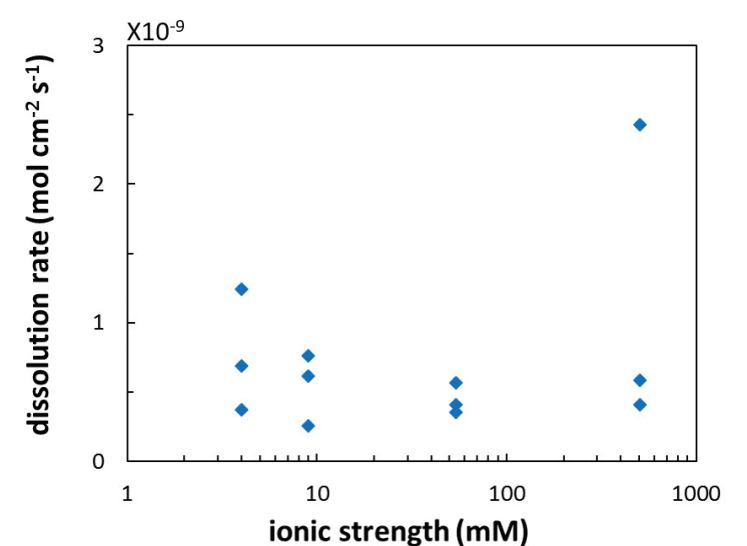

Figure 4 Chemical dissolution rate as a function of ionic strength. The rate is calculated from the AFM height change during the first 30 minutes of flow for regions that underwent dissolution only. The presence of EDTA significantly increases dissolution rates so the results cannot be compared to field rates. 
Although we do not observe a connection between grain detachment and salinity in our experiments, it has been shown that brittle rock strength, which is also related to repulsive forces (Røyne et al., 2015), is affected by the concentration of dissolved ions. Rostom et al. (2013) showed that at low ionic strength calcite becomes $20 \%$ weaker relative to its strength in deionised water; at high ionic strength $(>1 \mathrm{M})$ calcite becomes $30 \%$ stronger. While $\mathrm{NaCl}$ solutions can impact rock strength, other ion pairs could have a different effect (Bergsaker $e$ al., 2016). Thus, by increasing salinity or in the presence of other ionic species, a stronger impact on grain detachment might be observed.

\section{Conclusions}

We have shown that micrometre-sized grains detach from limestone surfaces under stagnant conditions, demonstrating that shear forces are not necessary to account for particle removal. Therefore, grain detachment is expected to occur in carbonate rocks exposed to reactive fluids under field conditions, even when there is little or no flow. Based on the range of hydraulic conductivities for limestone formations (Hiscock, 2005), interstitial velocity in many carbonate aquifers is expected to be low, ranging from $10^{-9}$ to $10^{-6} \mathrm{~m} \mathrm{~s}^{-1}$. As long as the fluids in such systems are reactive, a significant flux of calcium carbonate grains could enter the fluid phase as colloidal particles. Although particles released within the pore network of carbonate rocks are expected to be transported only short distances before being immobilised or dissolved, particles detached from fracture surfaces could have much greater mobility.

While grain detachment and movement can occur naturally, these processes could be enhanced during carbon sequestration in formations containing carbonate minerals or during the injection of saline or acidic fluids in enhanced oil recovery. At present, geochemical models do not account for the release and transport of carbonate particles, potentially affecting the prediction of solute transport and evolving porosity and permeability. Although our results suggest that including grain detachment could improve the accuracy of water-rock simulations in carbonate formations, determining if this mechanism is commonplace in other types of carbonate rocks remains a question for the future.

\section{Acknowledgements}

We are grateful for financial support from the Israel Science Foundation and the CAMBR fellowship. We also thank two anonymous reviewers and the editor for their constructive comments.

Editor: Susan Stipp

\section{Additional Information}

Supplementary Information accompanies this letter at www.geochemicalperspectivesletters.org/article1714

Reprints and permission information are available online at http://www. geochemicalperspectivesletters.org/copyright-and-permissions

Cite this letter as: Levenson, Y., Emmanuel, S. (2017) Repulsion between calcite crystals and grain detachment during water-rock interaction. Geochem. Persp. Let. 3, 133-141.

\section{References}

BergsaKer, A.S., Røyne, A., Ougier-Simonin, A., Aubry, J., Renard, F. (2016) The effect of fluid composition, salinity, and acidity on subcritical crack growth in calcite crystals. Journal of Geophysical Research: Solid Earth 121, 1631-1651.

Buhmann, D., Dreybrodt, W. (1987) Calcite dissolution kinetics in the system $\mathrm{H}_{2} \mathrm{O}-\mathrm{CO}_{2}-\mathrm{CaCO}_{3}$ with participation of foreign ions. Chemical Geology 64, 89-102.

CoOper, T.P., O'Brien, P.F., JefFrey, D.W. (1992) Rates of deterioration of Portland limestone in an urban environment. Studies in Conservation 37, 228-238.

EMMANUEL, S., LEVENSON, Y. (2014) Limestone weathering rates accelerated by micron-scale grain detachment. Geology 42, 751-754.

Emmanuel, S., AnovitZ, L.M., DaY-StiRrat, R.J. (2015) Effects of Coupled Chemo-Mechanical Processes on the Evolution of Pore-Size Distributions. Reviews in Mineralogy and Geochemistry $80,45-60$.

FORD, D., Williams, P. (2007) Karst Hydrogeology and Geomorphology. John Wiley \& Sons Ltd, Chichester.

Fredd, C.N., Fogler, H.S. (1998) The Influence of Chelating Agents on the Kinetics of Calcite Dissolution. Journal of Colloid and Interface Science 204, 187-197.

GLEDHILL, D.K., MorsE, J.W. (2006) Calcite dissolution kinetics in Na-Ca-Mg-Cl brines. Geochimica et Cosmochimica Acta 70, 5802-5813.

Hiscock, K.M. (2005) Hydrogeology: Principles and Practice. Blackwell Publishing, Malden, Oxford, Carlton.

LEVENSON, Y., EMMANUEL, S. (2016) Quantifying micron-scale grain detachment during weathering experiments on limestone. Geochimica et Cosmochimica Acta 173, 86-96.

Lomboy, G., Sundararajan, S., Wang, K., Subramaniam, S. (2011) A test method for determining adhesion forces and Hamaker constants of cementitious materials using atomic force microscopy. Cement and Concrete Research 41, 1157-1166.

LUQUOT, L. RODRIGUEZ, O, GOUZE, P. (2014) Experimental characterization of porosity structure and transport property changes in limestone undergoing different dissolution regimes. Transport in Porous Media 101, 507-532.

MorSE, J.W., ARVIDSON, R.S. (2002) The dissolution kinetics of major sedimentary carbonate minerals. Earth-Science Reviews 58, 51-84

Morse, J.W., ARvidson, R.S., LÜTTGE, A. (2007) Calcium carbonate formation and dissolution Chemical Reviews 107, 342-381. 
Nara, Y., NaKabayashi, R., Maruyama, M., Hiroyoshi, N., Yoneda, T., Kaneko, K. (2014) Influences of electrolyte concentration on subcritical crack growth in sandstone in water Engineering Geology 179, 41-49.

Oelkers, E.H., Golubev, S.V., PoKrovsky, O.S., BÉNÉZeth, P. (2011) Do organic ligands affect calcite dissolution rates? Geochimica et Cosmochimica Acta 75, 1799-1813.

Rostom, F., RøYNE, A., DYsTHE, D.K., RenARD, F. (2013) Effect of fluid salinity on subcritical crack propagation in calcite. Tectonophysics $583,68-75$.

RøYNE, A., DALBY, K.N., HASSENKAM, T. (2015) Repulsive hydration forces between calcite surfaces and their effect on the brittle strength of calcite-bearing rocks. Geophysical Research Letters 42, 4786-4794.

Ruiz-Agudo, E., Kowacz, M., Putnis, C.V., Putnis, A. (2010) The role of background electrolytes on the kinetics and mechanism of calcite dissolution. Geochimica et Cosmochimica Acta $74,1256-1267$.

VLeUGGELS, G., VAN GRIEKEN, R. (1995) Suspended matter in run-off water from limestone exposure setups. Science of the Total Environment 170, 125-132. 